\title{
Especies leñosas útiles de la selva baja caducifolia en la Sierra de Nanchititla, México
}

\section{Useful woody species from tropical deciduous forest in Sierra de Nanchititla, Mexico}

\author{
Carmen Zepeda Gómez" ${ }^{*}$ Cristina Burrola Aguilar², Laura White Olascoagal y Clarita Rodríguez Soto³
}

1 Universidad Autónoma del Estado de México. Facul-
tad de Ciencias. Toluca, Estado de México, México.
* Autor de correspondencia. zepedac(auaemex.mx

2 Universidad Autónoma del Estado de México. Centro de Investigaciones en Recursos Bióticos. Toluca, Estado de México, México.
3 Universidad Autónoma del Estado de México. Centro de Estudios e Investigación en Desarrollo Sustentable. Toluca, Estado de México, México

\section{RESUMEN}

Las selvas bajas caducifolias constituyen comunidades vegetales complejas y diversas, cuya distribución y permanencia se encuentra amenazada por las actividades humanas. La finalidad de esta investigación fue documentar el uso tradicional que tiene la flora leñosa y arborescente de la selva caducifolia de la Sierra de Nanchititla y, con ello, identificar especies potenciales para la recuperación, permanencia o aprovechamiento sustentable de las selvas caducifolias regionales. Se realizaron exploraciones etnobotánicas con la aplicación de entrevistas abiertas a informantes clave de poblados cercanos o incluidos en la Reserva Natural Sierra Nanchititla. Se registraron 137 especies útiles; nueve familias botánicas concentraron $58 \%$ de la flora; la familia con el mayor número de géneros y especies fue Fabaceae. Ochenta y cinco por ciento de las especies son nativas; el componente endémico exhibió el mayor número de especies $(30 \%)$, seguido del grupo de especies mesoamericanas $(26 \%$ ) y neotropicales $(21 \%)$. Se registraron nueve categorías de uso de la flora, los más frecuentes fueron el medicinal, para la construcción y la obtención de leña. De la flora, 32.8\% (45 especies) se encontró útil para tres o más propósitos, y Enterolobium cyclocarpum mostró el mayor número de usos (seis). Treinta y cuatro especies fueron citadas con uso alimenticio principalmente por los frutos que producen. Dieciséis especies se identifican con alto potencial para la restauración ecológica y la reforestación, dado que son especies nativas multipropósito e importantes prestadoras de servicios ambientales; su uso en programas de restauración podría satisfacer algunas demandas locales, mantener la cubierta arbórea y la diversidad local.

Palabras Clave: árboles, arbustos, bosque tropical, Cuenca del Balsas, etnobotánica, flora útil.

\section{ABSTRACT}

The tropical deciduous forests are highly diverse communities whose distribution and conservation status are compromised by human activities. The purpose of this research was to document the traditional use given to the woody and arborescent flora of the deciduous forests in Sierra de Nanchititla and to identify potential species for the recovery, permanence or sustainable use of the regional deciduous forests. The work was performed by ethnobotanical scans with the application of open interviews with key informants included in the Sierra Nanchititla Nature Reserve. One hundred thirty-seven useful woody species were recorded; nine botanical families grouped 58\% of the flora; Fabaceae was the family with the largest number of genera and species. From the recorded species, $85 \%$ are considered native to Mexico; the endemic component exhibited the greatest number of species (30\%), followed by Mesoamerican species (26\%) and Neotropical $(21 \%)$. Nine plant uses were recorded; the most frequent was medicinal followed by building and fuelwood uses. Of the flora, $32.8 \%$ (45 species) was useful for three or more purposes, Enterolobium cyclocarpum showed the greatest uses number (six). Thirty-four species were cited for food use primarily by their fruits production. Sixteen species have high ecological restoration and reforestation potential because they are multipurpose Mexican species and important providers of environmental services; its use in restoration programs could meet some local demands, maintain tree cover and local diversity.

KEYwORDs: trees, shrubs, tropical forest, Balsas, ethnobotany, useful flora. 


\section{INTRODUCCIÓN}

Las selvas bajas caducifolias (Miranda y Hernández-Xolocotzi, 1963), también nombradas bosques tropicales caducifolios o deciduos (Rzedowski, 2006), constituyen comunidades vegetales complejas altamente diversas. En México se consideran los ecosistemas tropicales mejor representados del país (Challenger y Soberón, 2008; Ceballos et al., 2010). Hace algunas décadas cubrían aproximadamente $17 \%$ del territorio nacional (Rzedowski, 2006), y las últimas estimaciones indican que su distribución potencial es cercana a $11.26 \%$ o un poco menos, pero menos de la tercera parte de ella se encuentra en una condición primaria (Challenger y Soberón, 2008). La extensión original de las selvas bajas caducifolias ha disminuido por el cambio de uso de suelo asociado a las actividades agrícolas y ganaderas, que, junto con las altas tasas de deforestación y los incendios, han deteriorado, fragmentado y aislado grandes extensiones de selva. Actualmente es el tipo de vegetación con el mayor peligro de desaparecer por completo del territorio nacional (Trejo y Dirzo, 2002; Trejo, 2010).

La mayor proporción de selvas bajas caducifolias de la República Mexicana se sitúa en la vertiente pacífica, desde Sonora y la parte sur de la Península de Baja California, hasta la depresión central de Chiapas (Rzedowski, 2006; Trejo, 2010). Hacia el interior del país importantes extensiones penetran sobre la Cuenca del Balsas cubriendo parte de los estados de Michoacán, Guerrero, Oaxaca, México, Morelos y Puebla. No menos importantes son los manchones de selvas caducifolias de Veracruz, Yucatán y Campeche, ubicados en la vertiente atlántica (Rzedowski, 2006; Trejo, 2010).

Típicamente, las selvas bajas caducifolias están dominadas por árboles de baja estatura (8 m - $12 \mathrm{~m}$ ), sus elementos predominantes son de origen neotropical y están adaptados a condiciones de sequía (Rzedowski, 2006). Fenológicamente, muestran una marcada estacionalidad asociada con la distribución anual de la precipitación: los arboles pierden las hojas en la época seca y reverdecen en la temporada de lluvias (Rzedowski, 2006). Se estima que cerca de $20 \%$ de la flora de México está presente en estos ecosistemas (Rzedowski, 1998); además, se calcula que 7.9\% de los géneros registrados en ellas (Rzedowski y Calderón, 2013) y un poco más de $40 \%$ de sus especies, son exclusivas de México (Rzedowski, 1991). El valor utilitario de su flora también es un indicador de su importancia, ya que más de $50 \%$ de sus especies son utilizadas (Maldonado, 1997; Dorado, 2000; Soto, 2010), entre las que destacan las especies con uso medicinal (Argueta, 1994). Su alto potencial utilitario también está asociado al uso de la flora como alimento, curtiente, ornamental, textil, condimentaría, así como maderable y forrajero (Soto, 2010).

En la Cuenca del Balsas las selvas bajas caducifolias conforman un territorio con altos niveles de diversidad florística (Rzedowski, 2006; Trejo y Dirzo, 2002; Trejo, 2010) y de endemismos regionales y locales (Bezaury, 2010); como parte de ella, la región de tierra caliente del Estado de México se ha descrito como un área florísticamente diversa (García, 1983; Torres y Trejo et al., 1998; Zepeda y Velázquez 1999; Juan-Pérez et al., 2005; LópezPatiño, López-Sandoval, Beltrán Retis y Aguilera Gómez, 2012; White-Olascoaga, Juan-Pérez. Chávez-Mejía y Gutiérrez-Cedillo, 2013; Rubí-Arriaga et al., 2014; Martínez De La Cruz, et al., 2015) y en la que es posible encontrar una importante cultura de uso de la flora. La zona de estudio corresponde a la Reserva Natural Sierra Nanchititla (RNSN), una zona que sobresale por formar parte de la Cuenca del Balsas, por ser la segunda Área Natural Protegida más grande del Estado de México (Comisión Estatal de Parques Naturales y de la Fauna [Cepanaf], 1997) y una de las pocas que en el país cuenta con selvas bajas caducifolias con fragmentos en estado relativamente bien conservado, condición que la ha colocado como una de las 36 áreas prioritarias para la conservación de selvas secas del Pacífico Mexicano (Salazar-Cerda, Monroy-Vilchis y Ceballos, 2010).

A escala nacional, los análisis etnobotánicos de las selvas bajas caducifolias son escasos. Estudios como los de Rico-Gray et al. (1991), Casas et al. (2001), MorenoCasasola y Paradowska (2009) y Soto (2010), muestran que en estos ecosistemas hay un conjunto de plantas que regionalmente se usan de forma constante y para diferen- 
tes propósitos (medicinales, comestibles, ornamentales, forrajeras, etc.), pero sobre todo, indican que el conocimiento tradicional que guardan los pobladores sobre el uso y manejo de las plantas locales puede ser una fuente de información valiosa para el diseño de estrategias de conservación y desarrollo social.

\section{OBJETIVOS}

La finalidad de este trabajo fue documentar el uso tradicional que tiene la flora leñosa y de hábito arborescente de las selvas bajas caducifolias de la Sierra de Nanchititla e identificar especies que por su demanda local pueden ser propuestas como especies potenciales para la recuperación, permanencia o aprovechamiento sustentable de este tipo de ecosistemas.

\section{MATERIALES Y MÉTODOS}

\section{Zona de estudio}

La Reserva Natural Sierra de Nanchititla (RNSN) se ubica al suroeste del Estado de México, en los límites con los estados de Guerrero y Michoacán, presenta un área aproximada de 66338 ha y pertenece a la región fisiográfica de la Cuenca del Balsas. Sus coordenadas extremas son $18^{\circ} 47^{\prime} 42^{\prime \prime}$ a $18^{\circ} 58^{\prime} 03^{\prime \prime} \mathrm{N}$, y $100^{\circ} 15^{\prime} 58^{\prime \prime}$ y $100^{\circ} 35^{\prime}$ 35" O (Fig. 1).

La vegetación de la RNSN está constituida principalmente por selva baja caducifolia $\left(209.98 \mathrm{~km}^{2}, 31.5 \%\right)$, bosques de latifoliadas $\left(91.13 \mathrm{~km}^{2}, 13.7 \%\right.$; se considera a los bosques de encino, mesófilo de montaña y de galería), bosque de pino-encino $\left(68.53 \mathrm{~km}^{2}, 10.3 \%\right)$, monocultivos y maíz $\left(259.66 \mathrm{~km}^{2}, 39.1 \%\right)$ y zonas de pastizales $(35.3$ $\mathrm{km}^{2}, 5.3 \%$ ) (Rubio-Rodríguez, 2009). La zona presenta un intervalo altitudinal entre los $500 \mathrm{~m}$ y los $1100 \mathrm{~m} \mathrm{snm}$, clima cálido subhúmedo con lluvias en verano y marcada estacionalidad climática (temporada de secas de noviembre a mayo y de lluvias de junio a octubre); la temperatura y precipitación media anual son de $25{ }^{\circ} \mathrm{C}$ y $1100 \mathrm{~mm}$, respectivamente.

El deterioro en el que se encuentran las selvas bajas caducifolias de la reserva las expone en fragmentos aisla-

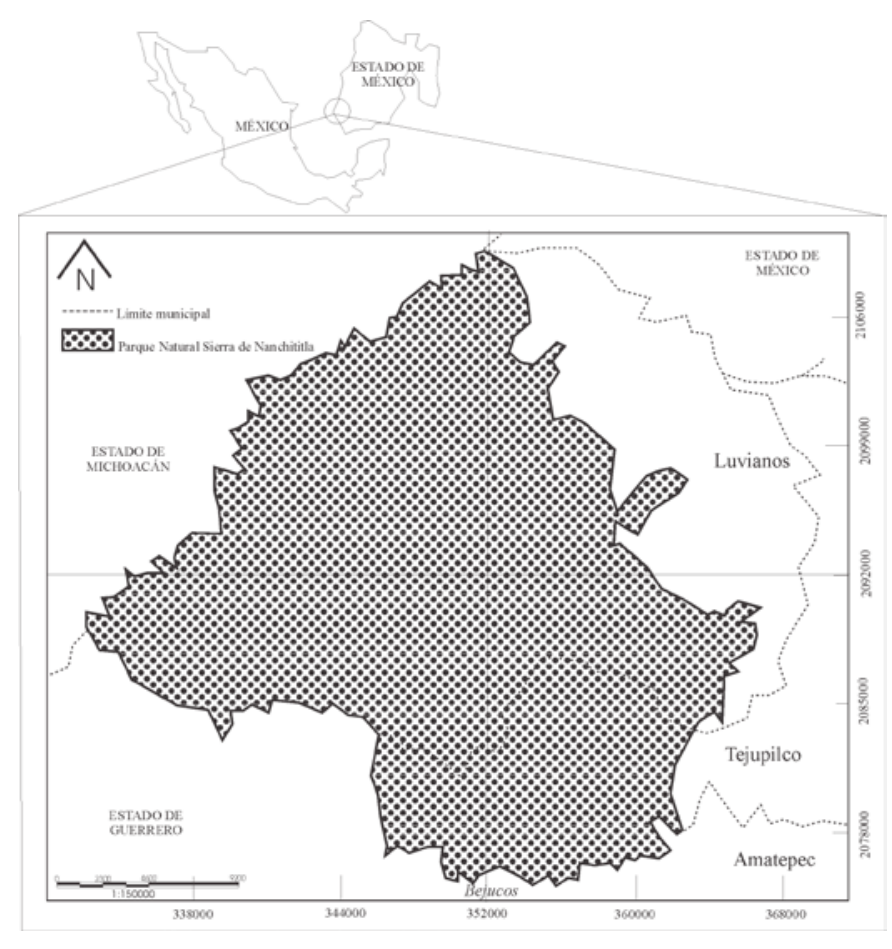

Figura 1. Ubicación de la zona de estudio.

dos de vegetación medianamente conservada, rodeados por pastizales inducidos y vegetación secundaria (Sistema Estatal de Áreas Naturales Protegidas Estado de México [Seanpem], 2016). La flora registrada incluye 296 especies de 87 familias y 214 géneros, de los cuales 266 especies son fanerógamas (234 dicotiledóneas y 32 monocotiledóneas) y 30 pteridofitas y plantas afines (Zepeda y Velázquez, 1999). Los pocos registros etnobotánicos regionales sugieren que la cultura de uso de las plantas se mantiene de forma importante entre los lugareños (García, 1983; Juan-Pérez et al., 2005; Rubí-Arriaga et al., 2014).

\section{Recolecta y determinación de especies}

Con el apoyo de informantes con conocimiento sobre plantas útiles de la región, de enero de 2008 a marzo de 2010 se realizaron caminatas etnobotánicas en las localidades de Bejucos, El Guayabal, Rincón del Guayabal, El Paso y Los Ciruelos. En total, se efectuaron 12 recorridos en los cuales se aplicaron 21 entrevistas abiertas a amas de casa mayores de 50 años y personas dedicadas a la medicina tradicional; todo esto con la intención de recabar información etnobotánica y colectar ejemplares botánicos 
de las especies leñosas y aquellas de hábito arborescente con algún uso. Dado que la selva baja caducifolia de estudio está formada por un mosaico de vegetación en diferentes estados de conservación, se consideraron las especies útiles que se encontraban en las áreas de vegetación natural y secundaria, así como en los huertos y potreros de la zona.

El material recolectado se procesó mediante las técnicas convencionales descritas en Lot y Chiang (1986). La identificación taxonómica se realizó con el uso de claves disponibles en bibliografía especializada (floras y monografías). Los ejemplares determinados se cotejaron con las colecciones de los herbarios ENCB (Herbario de la Escuela Nacional de Ciencias Biológicas del Instituto Politécnico Nacional) y MEXU (Herbario Nacional del Instituto de Biología de la Universidad Nacional Autónoma de México). Una serie completa de los ejemplares recolectados se depositó en el Herbario de la Facultad de Ciencias, de la Universidad Autónoma del Estado de México. Las familias se ordenaron según el sistema de clasificación del Angiosperm Phylogeny Group (2009). Las abreviaturas de los autores se citaron de acuerdo con Villaseñor, Ortiz y Redonda-Martínez (2008). La forma biológica se determinó siguiendo los criterios establecidos por Rzedowski (2006). El origen y la distribución geográfica de las especies (nativa o introducida) se determinaron a través de literatura florístico-taxonómica, así como del sitio web Tropicos del Missouri Botanical Garden; se usaron las categorías fitogeográficas propuestas Martínez-De la Cruz et al. (2015): Endémica de México (Mx), México a Centroamérica (Mx-cAm), México a Norteamérica (Mx-nAm), Norteamérica a Centroamérica (nAm-cAm), México a Sudamérica (Mx-sAm) y Norteamérica a Sudamérica (nAm-sAm). Las afecciones tratadas con las plantas medicinales citadas por los informantes se agruparon con base en una modificación hecha a la Clasificación Internacional de las Enfermedades del Manual de la Clasificación Estadística Internacional de Enfermedades y Causas de Defunción (Organización Mundial de la Salud [OMS], 1972).

Para determinar la importancia del uso de las plantas se siguió la metodología de la sumatoria de usos o usos totalizados modificada por Marín-Corba, CárdenasLópez y Suárez-Suárez (2005); para ello, se definieron nueve categorías de uso: alimenticio (especies cultivadas y de la selva usadas como comestibles), ornamento (especies para decoración de espacios), construcción y ebanistería (plantas usadas en la edificación de viviendas, producción de vigas, cercas, techos, etc. y usadas para fabricar muebles), productora de tintes, medicina (plantas usadas para tratar o prevenir enfermedades), forraje (plantas que sirven para alimento animal), producción de leña, sombra y otros usos (incluye especies con usos específicos y que no pueden ser catalogados en las otras categorías de uso definidas en el estudio). La lista de especies obtenida se cotejó con la Lista Recursos Genéticos Forestales emitido por la Comisión Nacional Forestal (Conafor) y la Organización de las Naciones Unidas para la Alimentación y la Agricultura (FAO, 2012) y los estudios de Vázquez-Yanez, Batís Muñoz, Alcocer-Silva, Gual-Díaz y Sánchez-Dirzo (1999) para determinar aquellas especies que, bajo los criterios de estos autores, son consideradas como especies prioritarias para la reforestación, con servicios ambientales o sociales y con valor para la reducción de la pobreza y la seguridad alimentaria.

\section{Resultados}

\section{Composición florística}

Se registraron 137 especies de plantas leñosas y de hábito arborescente útiles incluidas en 43 familias botánicas y 98 géneros (Tabla 1). De esta flora útil, $75 \%$ está formada por árboles o plantas de hábito arborescente, 23\% de arbustos y solo $2 \%$ de plantas trepadoras. Nueve familias presentaron cuatro o más especies y concentraron $58 \%$ de las plantas arbustivas y arbóreas de la zona (Fig. 2). Dentro de estas familias, Fabaceae, Burseraceae, Rubiaceae, Bignoniaceae y Anacardiaceae destacan por presentar el mayor número de especies, particularmente las fabáceas presentaron el mayor número de géneros y especies de toda la flora ( $23 \%$ y $22 \%$, respectivamente). Los géneros mejor representados fueron Bursera y Ficus, con trece y cinco especies cada uno. Destaca la presencia de dos espe- 
Tabla 1. Lista de especies leñosas y de hábito arborescente de la selva baja caducifolia de la Reserva Natural Sierra de Nanchititla.

\begin{tabular}{|c|c|c|c|c|c|}
\hline Familia y Especie & Distribución & $\begin{array}{c}\text { Forma } \\
\text { Biológica }\end{array}$ & Nombre Común & Usos & $\begin{array}{c}\text { Sumatoria } \\
\text { de usos }\end{array}$ \\
\hline \multicolumn{6}{|l|}{ Anacardiacea } \\
\hline Comocladia engleriana Loes & $\mathrm{Mx}$ & Ar & Tarlate blanco & 5 & 1 \\
\hline${ }^{*}$ Mangifera indica L. & Cultivada (Or. India) & Ar & Mango & $1,3,5,8$ & 4 \\
\hline Pseudosmodingium perniciosum (Kunth) Engl. & $\mathrm{Mx}$ & Ar & $\begin{array}{c}\text { Tarlate colorado, } \\
\text { Cuajiote }\end{array}$ & 5 & 1 \\
\hline 1Spondias mombin L. & Mx-sAm & Ar & Ciruelo de hueso & 1,5 & 2 \\
\hline
\end{tabular}

Annonaceae

*'Annona cherimola Mill.

Annona diversifolia Saff

*1Annona squamosa $\mathrm{L}$.

Apocynaceae

1,2Plumeria rubra $\mathrm{L}$.

Stemmadenia mollis Benth.

Thevetia ovata (Cav.) A.DC.

Bignoniaceae

'Astianthus viminalis (H.B.K.) Baitton

${ }^{1,2}$ Crescentia alata Kunth

Godmania aesculifolia (H.B.K.) Standl.

Parmentiera edulis DC

*Spathodea campanulata Beauv.

'Tabebuia guayacan (Seem.) Hemsl.

1,2Tabebuia rosea (Bertol.) DC.

'Tecoma stans (L.) Kunth

Bixaceae

1,2Cochlospermum vitifolium Willd. ex Spreng.

Mx-sAm

Mx

Cordia elaeagnoides DC.

américa)

Mx-cAm

Mx-cAm

Cultivada (Or. Perú
y Ecuador)
Mx-CAm

Cultivada (Or. Sud- Ar

$\mathrm{Mx}-\mathrm{CAm} \quad \mathrm{A}$

At

Cacalosuchitl

At

de gato

Solimán

$2,5 \quad 2$

$\begin{array}{ccccr}\text { Mx-cAm } & \text { Ar } & \text { Tirichicua, Azuchil } & 2 & 1 \\ \text { Mx-cAm } & \text { Ar } & \text { Carían } & 3,5,7 & 3 \\ \text { Mx-cAm } & \text { Ar } & \text { Cañafístula bofa } & 2,3 & 2 \\ \text { Mx-cAm } & \text { Ar } & \text { Cuajilote } & 3,5 & 2 \\ \text { Cultivada (Or. } & \text { Ar } & \text { Tulipán africano } & 2 & 2 \\ \text { África Tropical) } & & \text { Pr } & \text { Palo blanco } & 3,9 \\ \text { Mx-sAm } & \text { Ar } & \text { Cañafístula, } & 2,3,4,5 & 4 \\ \text { Mx-sAm } & & \text { Amapola } & \\ \text { nAm-sAm } & \text { At } & \text { Tronadora } & 2,3,5 & 3\end{array}$


Taвla 1. Lista de especies leñosas y de hábito arborescente de la selva baja caducifolia de la Reserva Natural Sierra de Nanchititla. Continuación...

\begin{tabular}{|c|c|c|c|c|c|}
\hline Familia y Especie & Distribución & $\begin{array}{c}\text { Forma } \\
\text { Biológica }\end{array}$ & Nombre Común & Usos & $\begin{array}{c}\text { Sumatoria } \\
\text { de usos }\end{array}$ \\
\hline Cordia morelosana Stand. & Mx & Ar & Chirare, Chirire & $2,3,5$ & 3 \\
\hline Cordia tinifolia Willd. & $M x$ & Ar & & 3 & 1 \\
\hline Tournefortia hartwegiana Steud. & Mx & At & & 5 & 1 \\
\hline \multicolumn{6}{|l|}{ Burseraceae } \\
\hline 1,2Bursera aff. simaruba (L.) Sarg. & $\mathrm{nAm}-\mathrm{sAm}$ & Ar & Guande verde & $3,5,7,9$ & 4 \\
\hline Bursera ariensis (Kunth) McVaugh \& Rzed. & $M x$ & Ar & & $3,7,9$ & 3 \\
\hline Bursera bicolor (Willd. ex Schltdl.) Engl. & Mx & Ar & & 7,9 & 2 \\
\hline Bursera bipinnata (Sessé \& Moc. ex DC.) Engl. & $\mathrm{Mx}-\mathrm{cAm}$ & Ar & Copal cimarrón & 7,9 & 2 \\
\hline \multirow[t]{2}{*}{ Bursera copallifera (Sessé \& Moc. ex DC.) Bullock } & $\mathrm{Mx}$ & $\operatorname{Ar}$ & Copal de penca, & 6,7 & 2 \\
\hline & & & Copal & & \\
\hline 'Bursera excelsa (Kunth) Engl. var. excelsa & Mx-cAm & $\operatorname{Ar}$ & & 7,9 & 2 \\
\hline Bursera fagaroides (Kunth) Engl. var. elongata & Mx & Ar & Cuajite verde & 5,7 & 2 \\
\hline \multicolumn{6}{|l|}{ McVaugh \& Rzed. } \\
\hline Bursera glabrifolia (Kunth) Engl. & Mx & $\operatorname{Ar}$ & Cuajiote & 5,7 & 2 \\
\hline Bursera grandifolia (Schltdl.) Engl. & $\mathrm{Mx}-\mathrm{cAm}$ & Ar & Guande & $5,7,9$ & 3 \\
\hline Bursera heteresthes Bullock & Mx-cAm & At & & 5,7 & 2 \\
\hline Bursera kerberi Engl. & Mx & $\operatorname{Ar}$ & & 7,9 & 2 \\
\hline Bursera trifoliolata Bullock & Mx & At & Cuincachire & 5,7 & 2 \\
\hline Bursera trimera Bullock & Mx & At & Copal & 7,9 & 2 \\
\hline \multicolumn{6}{|l|}{ Cactaceae } \\
\hline Neobuxbaumia mezcalaensis (Bravo) Backeb. & Mx & At & Órgano & 5 & 1 \\
\hline Opuntia lasiacantha Pfeifer & $M x$ & At & Nopal & 1,9 & 2 \\
\hline Stenocereus fricii Sanchez-Mejorada & Mx & At & Candelabro & 1,5 & 2 \\
\hline \multicolumn{6}{|l|}{ Caricaceae } \\
\hline 1,2Carica papaya $\mathrm{L}$. & Mx-sAm & $A b$ & Papaya & $1,5,6$ & 3 \\
\hline Jacaratia mexicana A.DC. & Mx-cAm & $\mathrm{Ar}$ & Bonete & 1,5 & 2 \\
\hline \multicolumn{6}{|l|}{ Casuarinaceae } \\
\hline *Casuarina cunninghamiana Miq. & $\begin{array}{c}\text { Cultivada (Or. Aus- } \\
\text { tralia) }\end{array}$ & Ar & & 2,9 & 2 \\
\hline \multicolumn{6}{|l|}{ Chrysobalanaceae } \\
\hline 1, ALicania arborea Seem. & Mx-sAm & Ar & Cacahuananche & $3,5,6,8$ & 4 \\
\hline \multicolumn{6}{|l|}{ Combretaceae } \\
\hline *1Terminalia catappa L. & $\begin{array}{c}\text { Cultivada (Or. } \\
\text { Sudeste de Asia) }\end{array}$ & Ar & Almendro & $2,3,4,8$ & 4 \\
\hline
\end{tabular}


Tabla 1. Lista de especies leñosas y de hábito arborescente de la selva baja caducifolia de la Reserva Natural Sierra de Nanchititla. Continuación...

\begin{tabular}{|c|c|c|c|c|c|}
\hline Familia y Especie & Distribución & $\begin{array}{c}\text { Forma } \\
\text { Biológica }\end{array}$ & Nombre Común & Usos & $\begin{array}{c}\text { Sumatoria } \\
\text { de usos }\end{array}$ \\
\hline \multicolumn{6}{|l|}{ Convolvulaceae } \\
\hline Ipomoea murucoides Roem. \& Schult & $M x-c A m$ & $\operatorname{Ar}$ & Cazahuate & 5,9 & 2 \\
\hline \multicolumn{6}{|l|}{ Erythroxylaceae } \\
\hline Erythroxylum mexicanum Kunth & $M x-c A m$ & $\operatorname{Ar}$ & Ocotillo & 3,9 & 2 \\
\hline \multicolumn{6}{|l|}{ Euphorbiaceae } \\
\hline Euphorbia fulva Stapf. & $M x$ & $\operatorname{Ar}$ & Pega hueso & 5,6 & 2 \\
\hline Euphorbia schlechtendalii Boiss. & $M x-c A m$ & At & Lecherilla & 7 & 1 \\
\hline Jatropha curcas L. & $M x-c A m$ & At & Palo hediondo & $2,5,7$ & 3 \\
\hline \multicolumn{6}{|l|}{ Fabaceae } \\
\hline Acacia cochliacantha Humb. \& Bonpl. & Mx & At & Cubata & 5 & 1 \\
\hline 1,2,3 Acacia farnesiana (L.) Willd. & Mx-sAm & At & Huizache & $3,4,5,9$ & 4 \\
\hline 'Andira inermis (Wright) Kunth ex DC. & $M x-C A m$ & $\operatorname{Ar}$ & Huijul, Cuiringuco & $2,3,5,8$ & 4 \\
\hline Bauhinia longiflora Rose & Mx & At & & 9 & 1 \\
\hline Bauhinia ungulata $\mathrm{L}$. & Mx-sAm & At & Pata de venado & 5 & 1 \\
\hline 'Caesalpinia coriaria Jacq. Willd. & Mx-sAm & $\mathrm{Ar}$ & Cascalate & $5,8,9$ & 3 \\
\hline *Caesalpinia pulcherrima (L.) Sw. & $\begin{array}{l}\text { Cultivada (Or. Amé- } \\
\text { rica Central) }\end{array}$ & At & $\begin{array}{c}\text { Surungano, Cirian- } \\
\text { guanico }\end{array}$ & $2,5,7,9$ & 4 \\
\hline Dalbergia congestiflora Pitt. & $M x-c A m$ & $\operatorname{Ar}$ & Granadillo & 3,4 & 2 \\
\hline \multirow[t]{2}{*}{ *Delonix regia (Borjer) Raf. } & Cultivada (Or. & $\mathrm{Ar}$ & Tabachin & $2,3,5$ & 3 \\
\hline & Madagascar) & & & & \\
\hline Entada polystachia (L.) DC. & Mx-sAm & $\mathrm{T}$ & Bejuco de paringue & 5 & 1 \\
\hline 1,3Enterolobium cyclocarpum (Jacq.) Griseb. & Mx-sAm & $\operatorname{Ar}$ & $\begin{array}{l}\text { Parota, guana- } \\
\text { castle }\end{array}$ & $1,3,5,6,8,9$ & 6 \\
\hline Erythrina americana Mil. & Mx & $\mathrm{Ar}$ & Colorín & $1,2,5$ & 3 \\
\hline Erythrina lanata Rose & Mx & $\operatorname{Ar}$ & Colorín & 2,5 & 2 \\
\hline 1,2,3Eysenhardtia polystachia (Ort.) Sarg. & $M x$ & $\operatorname{Ar}$ & Palo dulce & 5,7 & 2 \\
\hline 1,2,3 Gliricidia sepium (Jacq.) Steud. & $M x-s A m$ & $\operatorname{Ar}$ & Cacahuananche & $1,3,6,7$ & 4 \\
\hline Haematoxylum brasiletto Karsten & Mx-sAm & At & Palo Brasil & 4,5 & 2 \\
\hline Indigofera suffruticosa Mill. & nAm-sAm & At & Añil & 4,5 & 2 \\
\hline Inga eriocarpa Benth. & $M x$ & $\operatorname{Ar}$ & Quiebra hacha & 3,8 & 2 \\
\hline Leucaena esculenta (Moc. Et Sesse) Benth & $\mathrm{Mx}$ & $\operatorname{Ar}$ & Guaje & $1,5,7$ & 3 \\
\hline Leucaena glauca (I.) Benth & $n A m-s A m$ & $\mathrm{Ar}$ & Guaje & $1,3,6,7$ & 4 \\
\hline 'Lonchocarpus rugosus Benth. & $M x-c A m$ & $\operatorname{Ar}$ & Palo de aro & 7 & 1 \\
\hline 'Lysiloma acapulcensis (Kunth) Benth. & $M x-c A m$ & $\operatorname{Ar}$ & Tepehuaje & $3,6,7,9$ & 4 \\
\hline
\end{tabular}


Tавla 1. Lista de especies leñosas y de hábito arborescente de la selva baja caducifolia de la Reserva Natural Sierra de Nanchititla. Continuación...

\begin{tabular}{|c|c|c|c|c|c|}
\hline Familia y Especie & Distribución & $\begin{array}{c}\text { Forma } \\
\text { Biológica }\end{array}$ & Nombre Común & Usos & $\begin{array}{c}\text { Sumatoria } \\
\text { de usos }\end{array}$ \\
\hline 'Lysiloma divaricata (Jacq.) J.F.Macbr. & $M x-c A m$ & Ar & Palo blanco & $1,3,7,8$ & 4 \\
\hline Lysiloma tergemina Benth. & $M x-c A m$ & Ar & & $5,6,7$ & 3 \\
\hline Machaerium biovulatum Michel & Mx-sAm & At & & 9 & 1 \\
\hline Pithecellobium acatlense Benth. & $\mathrm{Mx}$ & Ar & Azinchite & 5,7 & 2 \\
\hline 1,2Pithecellobium dulce (Roxb.) Benth. & $M x-c A m$ & $\operatorname{Ar}$ & Pinzán & $1,3,5,6,7$ & 5 \\
\hline PPlatymiscium lasiocarpum Sand. & $M x$ & Ar & Granadillo & 3,4 & 2 \\
\hline Poeppigia procera Presl. & Mx-sAm & Ar & Parotilla & 3,9 & 2 \\
\hline Pterocarpus orbiculatus DC. & $M x$ & Ar & Oreja de elefante & 1,7 & 2 \\
\hline *Tamarindus indica $\mathrm{L}$. & $\begin{array}{c}\text { Cultivada (Or. } \\
\text { África) }\end{array}$ & Ar & Tamarindo & 1,8 & 2 \\
\hline \multicolumn{6}{|l|}{ Fagaceae } \\
\hline Quercus glaucoides M.Martens \& Galeotti & $\mathrm{nAm}-\mathrm{cAm}$ & Ar & & 7 & 1 \\
\hline \multicolumn{6}{|l|}{ Fouquieriaceae } \\
\hline Fouquieria formosa Kunth & $\mathrm{Mx}$ & Ar & & 7,9 & 2 \\
\hline \multicolumn{6}{|l|}{ Hernandiaceae } \\
\hline Gyrocarpus jatrophifolius Domin & $M x-c A m$ & Ar & & 3,7 & 2 \\
\hline \multicolumn{6}{|l|}{ Hippocrateaceae } \\
\hline Hippocratea celastroides Kunth & $M x-c A m$ & $\mathrm{~T}$ & Barajilla blanca & 5 & 1 \\
\hline \multicolumn{6}{|l|}{ Hydrophyllaceae } \\
\hline Wigandia caracasana Kunth & nAm-sAm & $\operatorname{Ar} \circ \mathrm{At}$ & & 9 & 1 \\
\hline \multicolumn{6}{|l|}{ Lamiaceae } \\
\hline 'Vitex mollis Kunth & $\mathrm{Mx}$ & Ar & Nanche de perro & 5 & 1 \\
\hline Vitex pyramidata Rob. & $M x$ & Ar & Querenda & 5 & 1 \\
\hline \multicolumn{6}{|l|}{ Lauraceae } \\
\hline Persea americana Mill. & $M x-c A m$ & $\operatorname{Ar}$ & & $1,5,9$ & 3 \\
\hline \multicolumn{6}{|l|}{ Malpighiaceae } \\
\hline 1,2Byrsonima crassifolia (L.) DC. & Mx-sAm & At o Ar & Nanche & $1,3,5,7$ & 4 \\
\hline Heteropterys laurifolia (L.) Juss. & Mx-sAm & Ato $\mathrm{T}$ & & 7 & 1 \\
\hline 'Malpighia glabra L & $M x-c A m$ & Aro At & & 5 & 1 \\
\hline \multicolumn{6}{|l|}{ Malvaceae } \\
\hline 'Ceiba acuminata (Watson) Rose & $M x-c A m$ & Ar & Ceiba & 3,8 & 2 \\
\hline 'Ceiba aesculifolia (H.b.K.)Britt et Baker & Mx-sAm & Ar & Puchote, pochote & $3,5,8$ & 3 \\
\hline 1,2,3 Guazuma ulmifolia Lam. & Mx-sAm & Ar & Cuahuilote, Guázima & $3,5,6,9$ & 4 \\
\hline Melochia Iupulina Sw. & Mx-sAm & At & & 7 & 1 \\
\hline
\end{tabular}


Tabla 1. Lista de especies leñosas y de hábito arborescente de la selva baja caducifolia de la Reserva Natural Sierra de Nanchititla. Continuación...

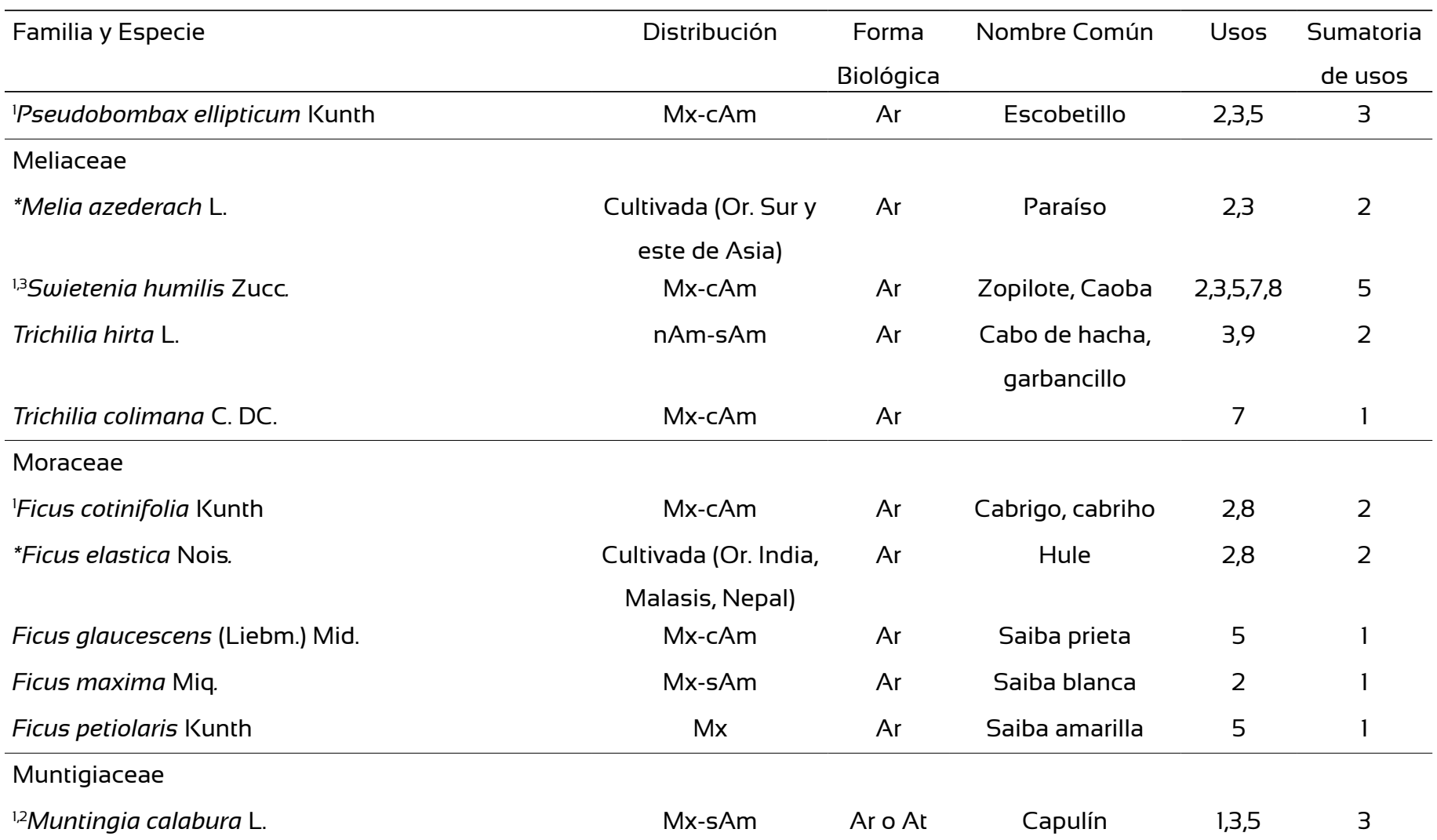

Myrsinaceae

Ardisia lindenii (Mez) Standl.

$M x \quad A t$

7

Myrtaceae

*Eucalyptus globulus Labill.

Cultivada (Or. Aus- $\quad$ Ar

Eucalipto

$2,5,8$

3

Myrthus sp.

Cultivada (Or

Ar

Arrayan

1,5

2

1Psidium guajava L.

Europa y África)

Musaceae

*Musa sapientum L.

Cultivada (Or. Asia)

Ar

Guayaba

1,5

2

Nyctaginaceae

*Bougainvillea glabra Choisy

Cultivada (Or. At Bugambilea

$2,5 \quad 2$

Brasil)

Piperaceae

*Piper scabrum Sw.

Cultivada

Ar

1,5

2

\section{Ranunculaceae}

Clematis dioica $\mathrm{L}$.

Mx-sAm

T

2

1

Rhamnaceae

Karwinskia humboldtiana (Roem. Schult.)

$\mathrm{nAm}-\mathrm{Mx}$

Ar

Tullidora

$1,3,5$

3 
Tавla 1. Lista de especies leñosas y de hábito arborescente de la selva baja caducifolia de la Reserva Natural Sierra de Nanchititla. Continuación...

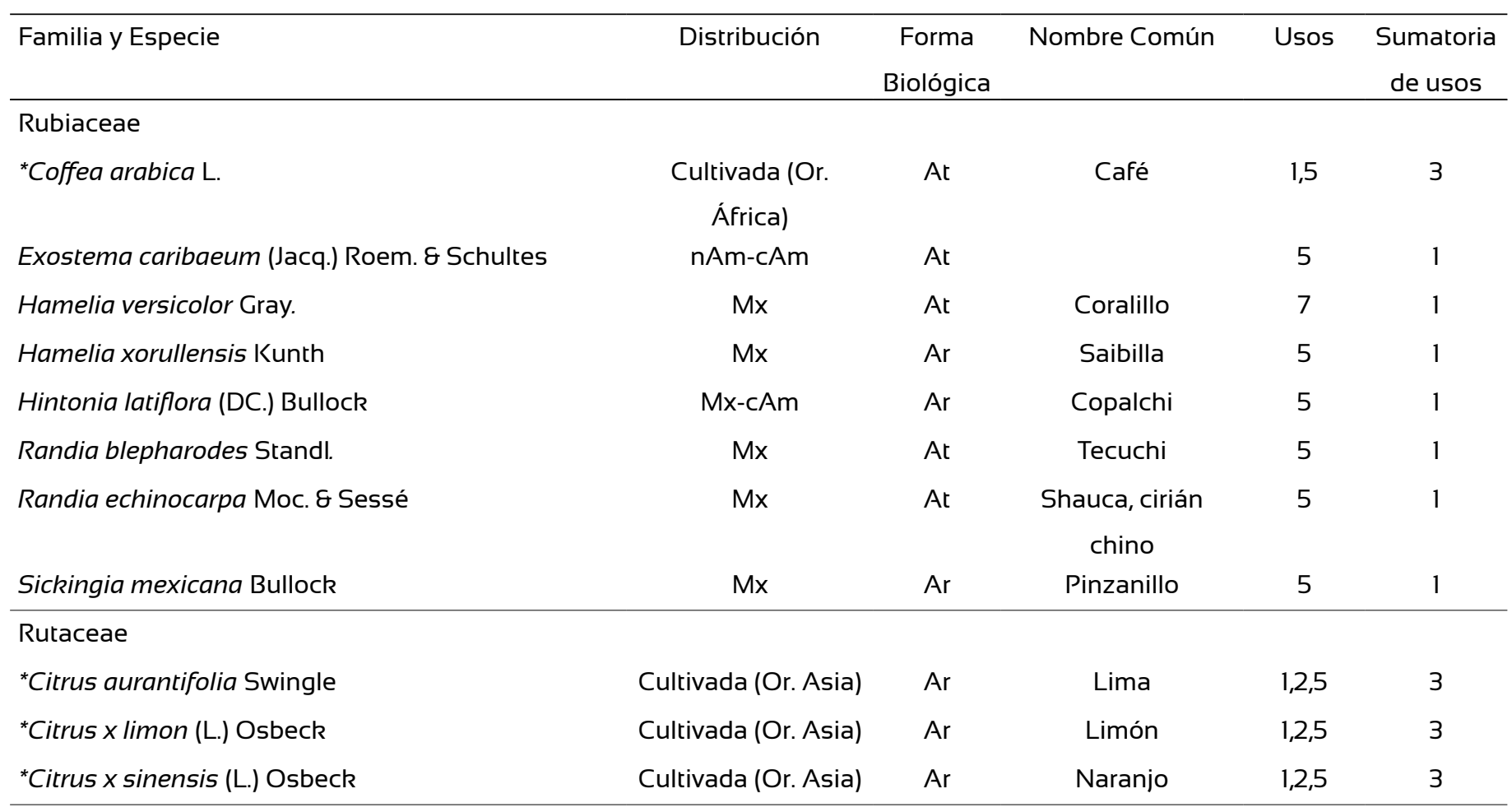

\section{Salicaceae}

Casearia corymbosa H.B.K.

Mx-CAm

At

Huevo de gato

7

1

Sapotaceae

'Pouteria campechiana (Kunth) Bachni

Mx-sAm Ar

Huicume

1,7

2

IPouteria sapota (L.) V. Royen

nAm-sAm

Ar

Zapote

$1,3,6,8$

4

ASideroxylon capiri (A.DC.) Pittier

Mx-sAm Ar

Capire

3,5

2

Simaroubaceae

Alvaradoa amorphoides Liebm.

$\mathrm{nAm}-\mathrm{cAm}$

Ar

Ardilla, Cola de

$3,5,8,9$

4

Ardilla

\begin{tabular}{|c|c|c|c|c|c|}
\hline Ternstroemia pringlei Rose & $M x$ & Ar & Flor de tila & 5 & 1 \\
\hline \multicolumn{6}{|l|}{ Ulmaceae } \\
\hline 1,2Trema micrantha (L.) Blume & Mx-sAm & Aro At & Capulín & $3,6,8$ & 3 \\
\hline \multicolumn{6}{|l|}{ Urticaceae } \\
\hline Urera caracasana (Jacq.) Griseb. & Mx-sAm & Ar & & 9 & 1 \\
\hline \multicolumn{6}{|c|}{ 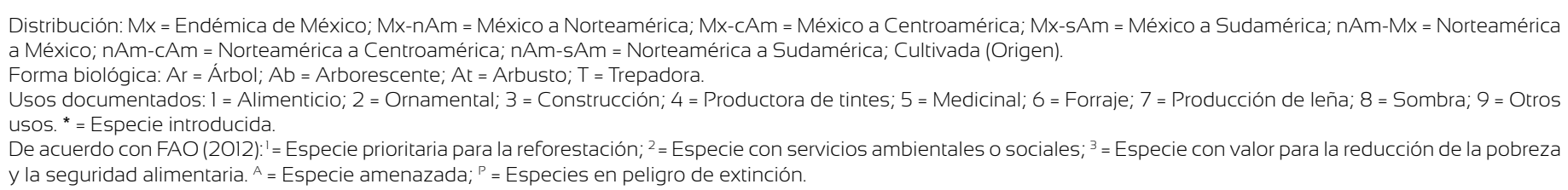 } \\
\hline
\end{tabular}




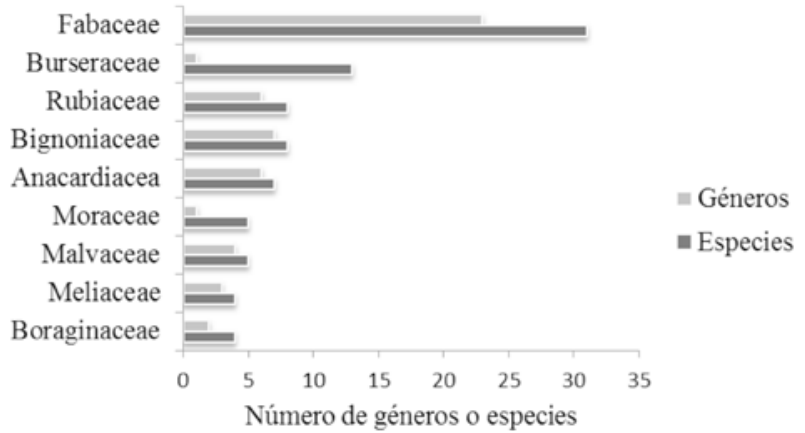

Figura 2. Número de especies y géneros de las familias más representativas de la selva baja caducifolia de la Reserva Natural Sierra de Nanchititla.

cies amenazadas (Sideroxylon capiri y Licania arbórea) y dos especies en peligro de extinción (Dalbergia congestiflora y Platymiscium lasiocarpum) según la NOM059-SEMARNAT-2010.

\section{Distribución geográfica y origen}

De las especies registradas, $85 \%$ corresponden a especies nativas que se distribuyen a lo largo del continente americano, desde Norteamérica hasta Sudamérica; el componente endémico presentó el mayor número de especies de la flora observada 41 (30\%), seguido del grupo de especies mesoamericanas $(26 \%, \mathrm{Mx}-\mathrm{cAm})$ y neotropicales $(21 \%$, Mx-sAm) (Fig. 3). Quince por ciento de las especies fue- ron plantas introducidas a México y actualmente cultivadas, algunas proceden del Viejo Mundo como Mangifera indica, Spathodea campanulata, Tamarindus indica, Terminalia catappa, Melia azederach, Ficus elastica, Coffea arabica y las tres especies del género Citrus (Tabla 1).

\section{Usos}

Se identificaron nueve categorías de usos de la flora (Fig. 4 y Tabla 1). El número de especies que se usan para cada categoría es variable. La flora útil puede tener de uno a seis usos diferentes (Prom. \pm Desv. Est. = $2.1 \pm 1.1$ usos); $68.6 \%$ de las especies presentó más de un uso y, de ellas, $32.8 \%$ (45 especies) se señaló como útil para tres o más propósitos (Fig. 4). Las especies que fueron nombradas en el mayor número de categorías de uso se consideran como las de mayor importancia, $13.8 \%$ (22 especies) presentó cuatro o más categorías de uso; Enterolobium cyclocarpum fue la especies con mayor número de usos (seis), seguida por Pithecellobium dulce y Swietenia humilis con cinco usos diferentes cada una. Los usos medicinales destacan por ser los más frecuentes, seguidos del uso para la construcción y la obtención de leña (Fig. 4).

Las afecciones más frecuentemente tratadas con las plantas medicinales de la zona son las enfermedades del aparato digestivo $(30.5 \%)$, seguidas de los signos y síntomas $(26.1 \%$; corresponden a manifestaciones de temperatura, dolor, nauseas etc. asociadas con diferentes
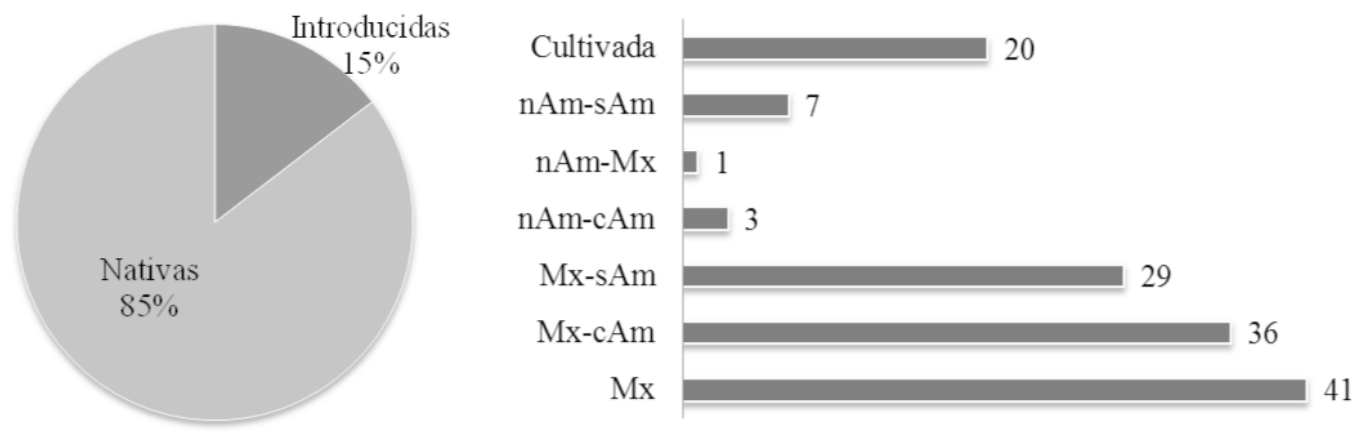

Figura 3. Área de distribución de las especies nativas e introducidas de la selva baja caducifolia de la Reserva Natural Sierra de Nanchititla. nAm: Norteamérica, sAm: Sudamérica, cAm: Centroamérica, Mx: Endémica de México. El porcentaje de especies cultivadas corresponden al de especies introducidas. 

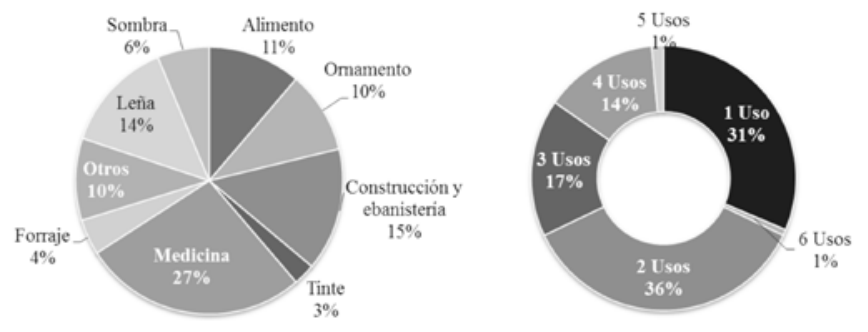

Figura 4. Usos de la flora leñosa y arborescente de la selva baja caducifolia de la Reserva Natural Sierra de Nanchititla. A) Porcentaje de especies por uso; B) Porcentaje de especies con 1-6 usos diferentes.

enfermedades o padecimientos) (Fig. 5). Treinta y cuatro especies fueron citadas con uso alimenticio principalmente por los frutos que producen, 16 de ellas son cultivadas. En general, las plantas mencionadas no se comercializan, algunas de ellas solo se venden ocasional y

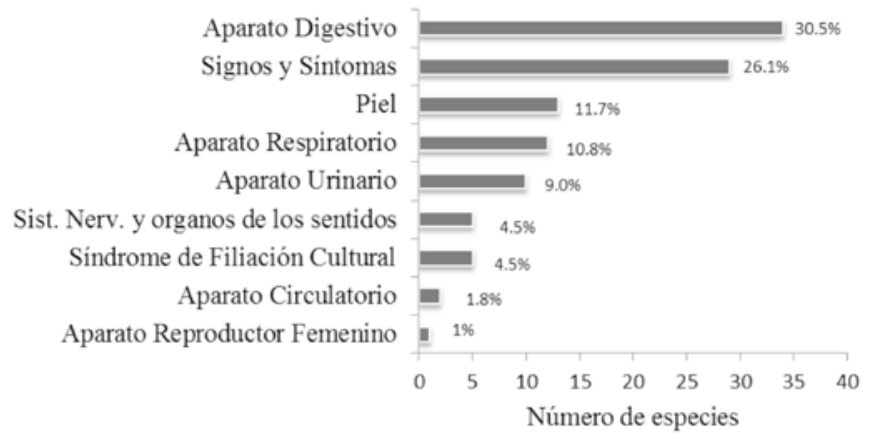

FiguRA 5. Usos medicinales de la flora leñosa y arborescente de la selva baja caducifolia de la Reserva Natural Sierra de Nanchititla.

localmente entre los vecinos, sin que esto represente un ingreso significativo.

Considerando el informe de la Situación de los Recursos Genéticos Forestales de México (RGF) emitido por la

Tabla 2. Especies de la selva baja caducifolia de Nanchititla con cuatro o más usos y reportadas en el informe de la Situación de los Recursos Genéticos Forestales de México (FAO, 2012) y Vázquez-Yanez et al. (1999).

\begin{tabular}{|c|c|c|c|}
\hline Especie & $\begin{array}{c}\text { Prioritaria para la } \\
\text { reforestación }\end{array}$ & $\begin{array}{l}\text { Con servicios ambien- } \\
\text { tales o sociales }\end{array}$ & $\begin{array}{l}\text { Con valor para la reducción de la } \\
\text { pobreza y la seguridad alimentaria }\end{array}$ \\
\hline Lysiloma acapulcensis (Kunth) Benth. & $x$ & & \\
\hline Lysiloma divaricata (Jacq.) J.F.Macbr. & $x$ & & \\
\hline Andira inermis (Wright) Kunth ex DC. & $\mathrm{x}$ & & \\
\hline Pouteria sapota (L.) V. Royen & $\mathrm{x}$ & & \\
\hline Licania arborea Seem. & $\mathrm{x}$ & & \\
\hline Terminalia catappa $\mathrm{L}$. & $x$ & & \\
\hline Tabebuia rosea (Bertol.) DC. & $\mathrm{x}$ & $\mathrm{x}$ & \\
\hline Cochlospermum vitifolium Willd. ex Spreng. & $x$ & $x$ & \\
\hline Bursera aff. simaruba (L.) Sarg. & $x$ & $x$ & \\
\hline Byrsonima crassifolia (L.) DC. & $x$ & $x$ & \\
\hline Pithecellobium dulce (Roxb.) Benth. & $x$ & $x$ & \\
\hline Enterolobium cyclocarpum (Jacq.) Griseb. & $x$ & & $x$ \\
\hline Swietenia humilis Zucc. & $x$ & & $x$ \\
\hline Acacia farnesiana (L.) Willd. & $x$ & $x$ & $x$ \\
\hline Gliricidia sepium (Jacq.) Steud. & $x$ & $x$ & x \\
\hline Guazuma ulmifolia Lam. & $x$ & $x$ & x \\
\hline
\end{tabular}


Conafor y la FAO (2012), así como por los reportes de Vázquez-Yanez et al. (1999), la lista de especies de la zona de estudio presenta 46 especies prioritarias para fines de conservación, reforestación y restauración, 15 importantes por los servicios ambientales documentados que ofrecen y 10 especies de valor para la seguridad alimentaria o para la reducción de la pobreza (Tabla 1). De las especies incluidas en el informe RGF, 16 presentaron más de cuatro usos en la zona de estudio (Tabla 1 y 2 ).

\section{DISCUSIÓN}

La información documentada para la selva baja caducifolia de la Sierra de Nanchititla indica que se trata de una comunidad vegetal con una flora leñosa y arborescente rica (137 especies) y ampliamente utilizada (Tabla 1 y Fig. 3). La composición florística obtenida de la zona de estudio difiere de la documentada para selvas bajas caducifolias de otras regiones de México, por ejemplo: Pineda-García, Arredondo-Amezcua y Ibarra-Manríquez (2007) registran 82 especies, 56 géneros y 24 familias de especies leñosas de la selva baja caducifolia de El Tarimo, Guerrero; Moreno-Casasola y Paradowska (2009) documentan 55 especies de árboles y palmas nativas útiles que crecen en las selvas bajas caducifolias y acahuales de las dunas costeras de Veracruz; Rocha-Loreto, RamírezMarcial y González-Espinosa et al. (2010) mencionan la presencia de 233 especies, 152 géneros y 57 familias de árboles en la depresión central de Chiapas, mientras que Méndez-Toribio, Martínez-Cruz, Cortés-Flores, RendónSandoval e Ibarra-Manríquez (2014) señalan la presencia de 78 especies, 50 géneros y 24 familias de árboles de la selva baja caducifolia de Tziritzícuaro, Michoacán. Las diferencias en la riqueza de especies de las localidades mencionadas se relacionan con las desigualdades de extensión, enfoque, métodos y esfuerzo de muestreo de cada uno de los estudios mencionados, así como con la alta diversidad florística local y regional de las selvas bajas caducifolias del país, asociada a las variaciones ambientales que prevalecen a lo largo de todo su rango de distribución (Challenger, 1998; Trejo y Dirzo, 2002; Trejo, 2005).
Más allá de la heterogeneidad florística propia de las selvas bajas caducifolias, la zona de estudio muestra algunos de los patrones generales reconocidos para este tipo de ecosistema y que deben resaltarse, entre ellos: una riqueza florística concentrada en pocas familias (Tabla 1) (Rzedowski y Calderón, 2013); el predominio de árboles y arbustos sobre plantas trepadoras (Tabla 1) (Trejo y Dirzo, 2002; Rzedowski, 2006; Méndez-Toribio et al., 2014); el dominio de elementos florísticos de afinidad neotropical (Tabla 1, Fig. 2); la importancia de la familia Fabaceae, y la alta frecuencia de uso de especies del género Bursera, así como de otras especies previamente registradas en la Cuenca del Balsas para selvas bajas caducifolias como: Amphypteringium adstringens, Cochlospermum vitifolium, Cordia elaeagnoides, Cytrocarpa procera, Pseudobombax ellipticum, entre otros (Miranda, 1947; Rzedowski, 2006). El predominio de la familia Fabaceae en la zona de estudio (Tabla 1 y Fig. 2) era esperado, ya que resulta ser la segunda familia más numerosa de plantas con flor en el país (Sousa y Delgado, 1993) y la que presenta el mayor número de especies arbóreas de las selvas bajas caducifolias de México (Lott, Bullock y SolísMagallanes, 1987; Trejo y Dirzo, 2002; Gallardo-Cruz et al., 2005; Rzedowski, 2006; Pineda-García et al., 2007; Méndez-Toribio et al., 2014; Rzedowski y Calderón, 2013), Centro y Sudamérica (Gillespie, Grijalva y Farris, 2000; Ruiz, Fandino y Chazdon, 2005). A nivel genérico tampoco sorprende encontrar que el taxón con mayor número de especies en Nanchititla sea Bursera (Tabla 1) ya que la cuenca del Balsas, a la que pertenece la zona de estudio, ha sido reconocida como centro de endemismo y diversificación de este género (Rzedowski, 1978, 1991; De-Nova et al., 2012).

En términos florísticos, las proporciones encontradas sobre la distribución geográfica de la flora tropical de la Sierra de Nanchititla confirma los reportes de Trejo (1998), y Rzedowski y Calderón (2013) sobre el hecho de que las selvas bajas caducifolias poseen una flora preponderantemente vinculada con la flora de Centro y Sudamérica (Fig. 3). Sobresale que la tercera parte de las especies citadas en la tabla 1 corresponden a especies endémicas; 
$50 \%$ pertenecientes a las familias Fabaceae, Burseraceae y Rubiaceae, que Rzedowski y Calderón (2013) consideran dentro las 14 mejor representadas en las selvas bajas caducifolias de México.

Otros taxa que se destacaron también en este estudio y que han sido clasificados previamente como de amplia distribución en el neotrópico, especialmente en los selvas secas son: Cordia y Lysiloma, que en la zona de estudio ocuparon el tercer lugar por el número de especies encontradas, así como Caesalpinia, Randia, Euphorbia, Jatropha, Leucaena, Lonchocarpus y Sideroxylon, todos mencionados por Rzedowski y Calderón (2013), entre los que contienen el mayor número de especies y que habitan preferencial o exclusivamente en la selva baja caducifolia de nuestro país.

Desde el punto de vista etnobotánico, la lista de especies de la zona de estudio incluye tanto elementos de comunidades vegetales naturales como aquellas en las que el humano interviene directa o indirectamente, de tal forma que tanto las especies silvestres como las cultivadas o protegidas por el hombre, aún juegan un papel utilitario de gran valor entre los pobladores de la Sierra de Nanchititla. En México, los estudios sobre el aprovechamiento de los recursos vegetales de las selvas bajas caducifolias son limitados (Soto, 2010; Moreno-Casasola y Paradowska, 2009), no obstante que se trata del ecosistema en el que se asienta la mayor población rural de México (Arias, Dorado y Maldonado, 2002) y del que se calcula que más de $50 \%$ de sus especies son útiles (Maldonado, 1997; Dorado, 2000; Soto, 2010). De acuerdo con los estudios de Soto (2010), en la Cuenca del Balsas los principales usos de la flora son los medicinales, alimenticios, maderables, ornamentales y forrajeros, una tendencia que es muy similar a la encontrada en la zona de estudio (Fig. 4) pero solo para especies arbóreas y arbustivas. Argueta (1994) menciona que la selva baja caducifolia es el ecosistema que aporta la mayor cantidad de plantas medicinales, como se observa en Yucatán (Rico-Gray, 1991) y la reserva de Tehuacán-Cuicatlán (Casas et al., 2001) donde el uso de plantas para remedios caseros es uno de los más importantes. En la zona de estudio, el uso medicinal sobresale como la forma más frecuen- temente citada por los lugareños, y en particular el de aquellas plantas para tratar enfermedades gastrointestinales, situación que coincide con el hecho de que estas enfermedades son una de las primeras causas de muerte en México y en el mundo, especialmente en zonas de pobreza y rezago social (Hernández, Aguilera y Castro, 2011).

El uso de los recursos celulósicos se mantiene como el segundo más importante de toda la flora de la zona de estudio; $14 \%$ de las especies son utilizadas para la construcción a pequeña escala (barandales, cercas, techos) y $13 \%$ para la obtención de leña. En otras regiones del país el aprovechamiento de la madera de las selvas bajas caducifolias se ubica dentro de los cinco usos más frecuentes (Rico-Gray, 1991; Casas et al., 2001; Moreno-Casasola y Paradowska, 2009), a pesar de que la mayoría de los árboles que crecen en estas selvas presentan un valor forestal reducido debido a su baja talla y diámetro pequeño, lo cual limita su explotación extensiva y dirige su aprovechamiento a la construcción a pequeña escala, a la obtención de leña o para la fabricación de utensilios o artesanías. El uso de la madera para leña aún es importante en la vida de las personas que aprovechan los recursos vegetales de las selvas bajas caducifolias de Nanchititla; de hecho, la alta valoración que los pobladores dan a este tipo de productos no solo es a nivel local sino también regional; Balvanera y Maas (2010) mencionan que la producción de leña como combustible en las selvas secas del Pacífico mexicano es de las más elevadas del país.

Además de proveer medicinas y materiales maderables, las selvas bajas caducifolias proporcionan diferentes recursos alimenticios (Balbavera y Maas, 2010), que en el caso de la zona de estudio se concentran en los frutos y semillas. Veintidós especies de las selvas bajas de Nanchititla se incluyen en el Catálogo de especies frutales del sureste del Estado de México (Rubí-Arriaga et al., 2014) y al menos 15 son cultivadas específicamente por los frutos que producen (Tabla 1). Algunas se consumen por temporadas, sobre todo aquellas que crecen silvestres (Byrsonima crassifolia, Muntingia calabura, Psidium guajava) y varias de ellas además se aprovechan esporádicamente para alimentar al ganado (Enterolobium cyclo- 
carpum, Guazuma ulmifolia, Carica papaya, Gliricidia sepium, Leucaena glauca y Pithecellobium dulce); el valor forrajero comprobado para Guazuma ulmifolia, Enterolobium cyclocarpum y algunas especies de los géneros Leucaena y Acacia (Flores, Bolivar, Botero y Murahim, 1998; Carranza Montaño, Sánchez-Velásquez, PinedaLópez y Cuevas, 2003), las coloca como fuentes alternativas con alto potencial para alimentar al ganado.

En la zona de estudio los huertos se presentan inmersos entre las áreas de vegetación natural y secundaria; se mantienen como sistemas de producción a pequeña escala, en los cuales se mezclan especies cultivadas con especies silvestres. Si bien no se identificó específicamente la flora que en ellos se concentra, los registros de regiones aledañas permiten asociar el valor utilitario que algunas especies de la zona podrían tener. Juan-Pérez et al. (2005) mencionan que los huertos de la Región Ecológica de Transición del Estado de México, a la que pertenece la zona de estudio, presentan 91 especies de árboles, arbustos y hierbas útiles, de los cuales 17 especies se hallan en la zona de Tejupilco, la mayoría de ellas aprovechadas por los frutos que producen, por su valor estético o por sus efectos microclimáticos. Además, desde el punto de vista ornamental, en el área analizada se encuentran 19 especies consideradas como potenciales de aprovechamiento por su belleza y apariencia general según GuadarramaMartínez et al. (2012).

En este sentido y como fuente importante de vitaminas, proteínas, minerales, aceites, antioxidantes (tanto para el hombre como para el ganado), medicinas, así como por la producción de leña y el valor estético y ecológico asociado a su hábito, algunos árboles de la zona de tierra caliente del sur del Estado de México citados en la tabla 1 y particularmente en la tabla 2 , podrían considerarse en el diseño y aplicación de estrategias de conservación, restauración y aprovechamiento de los recursos fitogenéticos regionales. De las especies encontradas en la zona de estudio, $85 \%$ se consideran nativas de México (Fig. 3); de acuerdo con los informes de la FAO (2012) y Vázquez-Yanez et al. (1999), 16 de ellas pueden considerarse con alto potencial para la restauración ecológica y la reforestación (Tabla 2), dado que son especies mexicanas multipropósito, es decir: especies prestadoras de servicios al ambiente, proveedoras de uno o varios productos útiles al hombre y con características prometedoras para emplearse en programas de restauración y reforestación en las diferentes regiones ecológicas del país (VázquezYanez et al., 1999).

Como se observa en los resultados, para las comunidades de la Sierra de Nanchititla, las selvas bajas caducifolias son una fuente importante de productos vegetales aprovechables, muchos de los cuales son parte de la diversidad biológica nativa. Pero como sucede en muchas zonas de México, su extracción intensa y desordenada ha ocasionado la disminución de los recursos y de los servicios ambientales que brindan. La conservación y restauración de la selva baja caducifolia de la zona de estudio es una tarea urgente por desarrollar; su éxito dependerá de la acción de diferentes actores como la academia, la industria y el gobierno, pero, sobre todo, de la participación de la población local, quienes a través de su vida cotidiana y conocimientos sobre el uso de la vegetación pueden contribuir al aprovechamiento sustentable y la conservación de la selva.

\section{CONCLUSIONES}

El presente trabajo muestra que la población que interactúa con los recursos de la Sierra de Nanchititla mantiene numerosos conocimientos empíricos sobre el uso y aprovechamiento de los árboles y arbustos nativos de las selvas bajas caducifolias de México; destaca la presencia de especies multipropósito y la alta frecuencia de uso de plantas como medicinales, para la construcción y obtención de leña. El riesgo de desaparición completa de las selvas bajas caducifolias, de su diversidad y del conocimiento del uso de sus recursos en el sur del Estado de México es alto. La información que actualmente existe es poca y fragmentada; no obstante, es indispensable profundizar en los conocimientos tradicionales sobre usos y manejos de las especies leñosas de la zona, dado que son la base de los programas de manejo y recuperación de comunidades vegetales sustentables que demandan urgentemente las 
selvas de la región. Se propone que los programas de manejo, conservación y aprovechamiento regionales consideren especies mexicanas multipropósito ya que su uso permitirá satisfacer algunas demandas locales, así como mantener la cubierta arbórea y con ello la conservación de la diversidad local, garantizando al mismo tiempo el mantenimiento de los servicios ambientales de la selva.

\section{RECONOCIMIENTOS}

A la Universidad Autónoma del Estado de México por las facilidades otorgadas y a los revisores anónimos por las aportaciones que enriquecieron el documento final.

\section{REFERENCIAS}

Angiosperm Phylogeny Group. (2009). An update of the Angiosperm phylogeny group classification for the orders and families of flowering plants: APG III. Botanical Journal of the Linnean Society, 161(2), 105-121. doi: 10.1111/j. 1095-8339.2009.00996.x

Argueta, A. (1994). Atlas de las plantas de la medicina tradicional mexicana. Tomos I, II y III. Ciudad de México, México: Instituto Nacional Indigenista.

Arias, D., Dorado, O. y Maldonado, B. (2002). Biodiversidad e importancia de la selva baja caducifolia de la Reserva de la Biosfera Sierra de Huautla. Biodiversitas, 45, 7-12.

Balvanera, P. y Maass, M. (2010). Los servicios ecosistémicos que proveen las selvas secas. En G. Ceballos, L. Martínez, A. García, E. Espinoza, J. Bezaury y R. Dirzo, Diversidad, amenazas y áreas prioritarias para la conservación de las selvas secas del Pacífico de México (1a ed., pp. 251270). Ciudad de México, México: Fondo de Cultura Económica-Comisión Nacional para el Conocimiento y Uso de la Biodiversidad.

Bezaury, C. (2010). Las selvas secas del pacifico mexicano en el contexto mundial. En G. Ceballos, L. Martínez, A. García, E. Espinoza, C. Bezaury y R. Dirzo, Diversidad, amenazas y áreas prioritarias para la conservación de las selvas secas del Pacífico de México (1a ed., pp. 22-40). Ciudad de México, México: Fondo de Cultura Económica-Comisión Nacional para el Conocimiento y Uso de la Biodiversidad.
Carranza-Montaño, M., Sánchez-Velásquez, M., Pineda-López, R. y Cuevas, G. (2003). Forage quality and potential of species from the sierra de Manantlan (Mexico) tropical dry forest. Agrociencia, 37(2), 203-210.

Casas, A., Valiente-Banuet, A., Viveros, J., Caballero, J., Cortés, L. y Dávila, P. et al. (2001). Plant resources of the Tehuacán-Cuicatlán Valley, Mexico. Economic Botany, 55(1), 129-166. doi: 10.1007/BF02864551

Ceballos, G., Martínez, L., García, A., Espinoza, E., Bezaury, J. y Dirzo, R. (2010). Diversidad, amenazas y áreas prioritarias para la conservación de las selvas secas del Pacífico de México. (1a ed.). Ciudad de México, México: Fondo de Cultura Económica-Comisión Nacional para el Conocimiento y Uso de la Biodiversidad.

Challenger, A. (1998). Utilización y conservación de los ecosistemas terrestres de México: pasado, presente y futuro. Ciudad de México, México: Comisión Nacional para el Conocimiento y Uso de la Biodiversidad-Universidad Nacional Autónoma de México -Agrupación Sierra Madre, S.C.

Challenger, A. y Soberón, J. (2008). Los ecosistemas terrestres, en Capital natural de México, Vol. I: Conocimiento actual de la biodiversidad. (pp. 87-108). Ciudad de México, México: Comisión Nacional para el Conocimiento y Uso de la Biodiversidad.

Comisión Estatal de Parques Naturales y de la Fauna [Cepanaf]. (2016). Áreas Naturales. Recuperado de http://www. angelfire.com/ar/cepanaf

De-Nova, J., Medina, R., Montero, J., Weeks, A., Rosell, J. y Olson, M. et al. (1939). Insights into the historical construction of species-rich Mesoamerican seasonally dry tropical forests: the diversification of Bursera (Burseraceae, Sapindales). New Phytologist, 193, 276-287. doi: 10.1111/j.1469-137.2011.03909.x

Dirzo, R. (1994). Mapa de vegetación de la cuenca del Río Cutzamala (Tesis de licenciatura). Universidad Autónoma del Estado de Morelos.

Dorado, R. (2000). Conservación de la biodiversidad en el México rural: Reserva de la Biosfera Sierra de Huautla, Morelos. En H. Monroy, H. Colín y D. Boyas, Los sistemas agroforestales de Latinoamérica y la selva baja cadu- 
cifolia en México (1a ed., pp. 166-185). Cuernavaca, México: Universidad Autónoma del Estado de Morelos.

Flores, O., Bolivar, D., Botero, J. y Murahim, M. (1998). Parámetros nutricionales de algunas arbóreas leguminosas y no leguminosas con potencial forrajero para la suplementación de rumiantes en el trópico. Livestock research for rural development, 10(1), 1-7.

Gallardo-Cruz, J., Pérez-García, F. y Meave, J. (2009). $\beta$-Diversity and vegetation structure as influenced by slope aspect and altitude in a seasonally dry tropical landscape. Landscape Ecology, 24, 473-482. doi: 10.1007/s10980-009-9332-1

García, I. (1983). Contribución al conocimiento de los árboles $y$ arbustos de Bejucos, Estado de México (Tesis de licenciatura). Universidad Nacional Autónoma de México.

Gillespie, T., Grijalva, A. y Farris, C. (2000). Diversity, composition, and structure of tropical dry forests in Central America. Plant Ecology, 147, 37-47.

Guadarrama-Martínez, N., Rubí-Arriaga, M., GonzálezHuerta, A., Vázquez-García, L., Martínez-De La Cruz, I., López-Sandoval, J. y Hernández-Flores, G. (2012). Inventario de árboles y arbustos con potencial ornamental en el sureste del estado de México. Phyton, 81, 221-228.

Hernández, C., Aguilera, M. y Castro, G. (2011). Situación de las enfermedades gastrointestinales en México. Enfermedades Infecciosa y Microbiología, 34, 137-151.

Juan-Pérez, J. y Madrigal-Uribe, D. (2005). Huertos, diversidad y alimentación en una zona de transición ecológica del estado de México. Ciencia Ergo Sum, 12(1), 54-63.

López-Patiño, E., López-Sandoval, J., Beltrán Retis, A. y Aguilera Gómez, L. (2012). Composición de la flora arbórea en el área natural protegida Tenancingo-Malinalco-Zumpahuacán. Estado de México. Polibotánica, 34, 51-98.

Lot, A. y Chiang, F. (1986). Manual de herbario. Administración y manejo de colecciones, técnicas de recolección y preparación de ejemplares botánicos. Ciudad de México, México: Consejo Nacional de la Flora de México.

Lott, E., Bullock, S. y Solís-Magallanes, J. (1987). Floristic diversity and structure of upland and arroyo forests of coastal Jalisco. Biotropica, 19, 228-235. doi: $10.2307 / 2388340$
Maldonado, A. (1997). Aprovechamiento de los recursos florísticos de la Sierra de Huautla, Morelos (Tesis de maestría). Universidad Nacional Autónoma de México.

Marín-Corba, C., Cárdenas-López, D. y Suárez-Suárez, S. (2005). Utilidad del valor de uso en etnobotánica. Estudio en el departamento de Putumayo (Colombia). Caldasia, 27(1), 89-101.

Martínez-De la Cruz, I., Vibrans, H., Lozada-Pérez, L., Romero-Manzanares, A., Aguilera-Gómez, L. y RivasManzano, I. (2015). Plantas ruderales del área urbana de Malinalco, Estado de México. Botanical Sciences, 93(4), 907-919. doi: 10.17129/botsci.213

Méndez-Toribio, M., Martínez-Cruz, J., Cortés-Flores, F., Rendón-Sandoval, J. e Ibarra-Manríquez, G. (2014). Composición, estructura y diversidad de la comunidad arbórea del bosque tropical caducifolio de Tziritzícuzro, Depresión del Balsas, Michoacán. Revista Mexicana de Biodiversidad, 85, 1117-1128. doi: 10.7550/rmb.43457

Miranda, F. (1947). Estudios sobre la vegetación de México. V. Rasgos de la vegetación en la cuenca del río de las Balsas. Revista De La Sociedad Mexicana de Historia Natural, $8,95-114$

Miranda, F. y Hernández-Xolocotzi, E. (1963). Los tipos de vegetación de México y su clasificación. Boletín de la Sociedad Botánica de México, 28, 29-179.

Moreno-Casasola, P. y Paradowska, K. (2009). Especies útiles de la selva baja caducifolia en las dunas costeras del centro de Veracruz. Maderas y Bosques, 15(3), 21-44. doi: $10.21829 /$ myb.2009.1531184

Organización de las Naciones Unidas para la Alimentación y la Agricultura [FAO]. (2016). Situación de los Recursos Genéticos Forestales en México. Recuperado de http:// www.fao.org/3/a-be793s

Organización Mundial de la Salud [OMS]. (2016). Clasificación estadística internacional de enfermedades y problemas relacionados con la salud (10a ed.). Washington, Estados Unidos: OPS.

Pineda-García, F., Arredondo-Amezcua, L. y Ibarra-Manríquez, G. (2007). Riqueza y diversidad de especies leñosas del bosque tropical caducifolio El Tarimo, Cuenca del Balsas, Guerrero. Revista Mexicana de Biodiversidad, 78, 129-139. 
Phillips, O. (1996). Some quantitative methods for analyzing ethnobotanical knowledge. En M. Alexiades (Ed.), Selected guidelines for ethnobotanical research: a field manual. Nueva York, Estados Unidos: The New York Botanical Garden.

Rico-Gray, V., Chemás, A. y Mandujano, S. (1990). Uses of tropical deciduous forest species by the Yucatecan Maya. Agroforestry Systems, 14(2), 149-161. doi: 10.1007/ BF00045730

Rocha-Loredo, A., Ramírez-Marcial, N. y González-Espinosa, M. (2010). Riqueza y diversidad de árboles del bosque tropical caducifolio en la Depresión Central de Chiapas. Boletín De La Sociedad Botánica De México, 87, 89-113. Rubí-Arriaga, M., González Huerta, A., Martínez-De la Cruz, I., Franco-Mora, O., Ramírez-Dávila, J., López-Sandoval, J. y Hernández-Flores, G. (2014). Inventario de especies frutales y aspectos etnobotánicas en Sultepec, Estado de México. Phyton, 82, 203-311.

Rubio-Rodríguez, R. (2009). Regionalización biótica, abiótica y social del Parque Natural Sierra Nanchititla, México: propuesta de conservación (Tesis de maestría). Universidad Autónoma del Estado de México.

Ruiz, J., Fandino, M. y Chazdon, R. (2005). Vegetation structure, composition, and species richness across a 56-year chronosequence of dry tropical forest on Providencia Island, Colombia. Biotropica, 37, 520-530. doi: 10.1111/j.1744-429.2005.00070.x

Rzedowski, J. (1991). El endemismo en la flora fanerogámica mexicana: una apreciación analítica preliminar. Acta Botánica Mexicana, 15, 47-64.

Rzedowski, J. (2016). Diversidad y orígenes de la flora fanerogámica de México. En T. Ramamoorthy, R. Bye, A. Lot y J. Fa, Diversidad Biológica de México: orígenes y distribución (1a ed., pp. 129-145). Ciudad de México, México: Instituto de Biología, Universidad Nacional Autónoma de México.

Rzedowski, J. (2006). Vegetación de México (1a ed.). Ciudad de México, México: Comisión Nacional para el Conocimiento y Uso de la Biodiversidad. Recuperado de http:// www.biodiversidad.gob.mx

Rzedowski, J. y Calderón de Rzedowski, G. (2013). Datos para la apreciación de la flora fanerógama del bosque tropical caducifolio de México. Acta Botánica Mexicana, 102, $1-23$.

Salazar-Cerda, I., Monroy-Vilchis, O. y Ceballos, G. (2010). Sierra de Nanchititla, Estado de México y Guerrero. En G. Ceballos Dirzo, L. Martínez, A. García, E. Espinoza, J. Bezaury y R. Dirzo, Diversidad, amenazas y áreas prioritarias para la conservación de las selvas secas del Pacífico de México (1st ed., pp. 471-473). Ciudad de México, México: Fondo de Cultura Económica-Comisión Nacional para el Conocimiento y Uso de la Biodiversidad.

Sistema Estatal de Áreas Naturales Protegidas Estado de México (SEANPEM). (2016). Sierra de Nanchititla. Recuperado de http://areasnaturales.edomex.gob.mx/sierra_nanchititla

Soto, J. (2010). Plantas útiles de la cuenca del Balsas. En G. Ceballos Dirzo, L. Martínez, A. García, E. Espinoza, J. Bezaury y R. Dirzo, Diversidad, amenazas y áreas prioritarias para la conservación de las selvas secas del Pacífico de México (1a ed., pp. 285-320). Ciudad de México, México: Fondo de Cultura Económica. Comisión Nacional para el Conocimiento y Uso de la Biodiversidad.

Sousa, S. y Delgado, A. (2016). Leguminosas mexicanas: fitogeografía, endemismo y orígenes. En T. Ramamoorthy, R. Bye, A. Lot y J. Fa, Diversidad biológica de México, orígenes y distribución (1st ed., pp. 449-493). Ciudad de México, México: Instituto de Biología, Universidad Nacional Autónoma de México.

Torres, M. y Tejero, J. (1998). Flora y vegetación de la Sierra de Sultepec, Estado de México. Anales Instituto De Biología. Serie Botánica Universidad Nacional Autónoma de México, 69(2), 135-174.

Trejo, I. (1998). Distribución y diversidad de selvas bajas de México: relaciones con el clima y con el suelo (Tesis de doctorado). Universidad Nacional Autónoma de México.

Trejo, I. (2005). Análisis de la diversidad de la selva baja caducifolia en México. En G. Halffter Salas, J. Soberon, P. Koleff y A. Melic, Sobre diversidad biológica: el significado de las diversidades alfa, beta y gamma (1st ed., pp. 111-122). Ciudad de México, México: m3m-Monografías Tercer milenio, Sociedad Entomológica Aragonesa, Zaragoza/ Conabio/ Grupo Diversitas-México/ Conacyt. 
Trejo, I. (2010). Las selvas secas del Pacífico Mexicano. En G. Ceballos Dirzo, L. Martínez, A. García, E. Espinoza, J. Bezaury y R. Dirzo, Diversidad, amenazas y áreas prioritarias para la conservación de las selvas secas del Pacífico de México (1a ed., pp. 41-51). Ciudad de México, México: Fondo de cultura económica-Comisión Nacional para el Conocimiento y Uso de la Biodiversidad.

Trejo, I. y Dirzo, R. (2002). Floristic diversity of Mexican seasonally dry tropical forests. Biodiversity and Conservation, 11, 2063-2084. doi. 10.1023/A:1020876316013

Tropicos del Missouri Botanical Garden. (2016). Tropicos.org. Recuperado de http://www.tropicos.org

Vázquez-Yánez, C., Batís Muñoz, A., Alcocer-Silva, M., GualDíaz, M. y Sánchez-Dirzo, C. (1999). Árboles y arbustos nativos potencialmente valiosos para la restauración ecológica y la reforestación. Ciudad de México, México: Comisión Nacional para el Conocimiento y Uso de la Biodiversidad.

Villaseñor, J., Ortiz, E. y Redonda-Martínez, R. (2008). Catálogo de autores de plantas vasculares de México. Ciudad de México, México: Instituto de Biología, Universidad Nacional Autónoma de México.
White-Olascoaga, L., Juan-Pérez, J., Chávez-Mejía, C. y Gutiérrez-Cedillo, J. (2013). Flora medicinal de San Nicolás, Municipio de Malinalco, Estado de México. Polibotánica, 35, 173-206.

Zepeda, C. y Velázquez, E. (1999). El bosque tropical caducifolio de la vertiente sur de la Sierra de Nanchititla, Estado de México; la composición y la afinidad geográfica de su flora. Acta Botánica Mexicana, 46, 29-55.

Zepeda-Gómez, C. (1994). Contribución al conocimiento de la Flora del bosque tropical caducifolio de la vertiente sur de la Sierra de Nanchititla (Tesis de licenciatura). Universidad Autónoma del Estado de México.

Manuscrito recibido el 11 de octubre de 2016. Aceptado el 19 de mayo de 2017.

Este documento se debe citar como:

Zepeda Gómez, C., Burrola Aguilar, C., White Olascoaga, L. y Rodríguez Soto, C. (2017). Especies leñosas útiles de la selva baja caducifolia en la Sierra de Nanchititla, México. Madera y Bosques, 23(3), 101-119. doi: 10.21829/myb.2017.2331426 